\title{
Modeling Adoption and Usage of Mobile Money Transfer Services in Kenya Using Structural Equations
}

\author{
Joseph Kuria Waitara, Anthony Gichuhi Waititu, Anthony Kibera Wanjoya
}

School of Mathematics, Jomo Kenyatta University of Agriculture and Technology, Nairobi, Kenya

\section{Email address:}

jkjoseph834@gmail.com (J. K. Waitara), agwaititu@gmail.com (A. G. Waititu), awanjoya@gmail.com (A. K. Wanjoya)

\section{To cite this article:}

Joseph Kuria Waitara, Anthony Gichuhi Waititu, Anthony Kibera Wanjoya. Modeling Adoption and Usage of Mobile Money Transfer Services in Kenya Using Structural Equations. American Journal of Theoretical and Applied Statistics. Vol. 4, No. 6, 2015 , pp. 513-526. doi: $10.11648 /$ j.ajtas.20150406.22

\begin{abstract}
Mobile Money Transfer services have eased the means of transferring money from one mobile phone user to another in Kenya. Since the introduction of the services there is disparity in adoption of different mobile money transfer platforms in Kenya. In this study Structural Equation Modeling was used to create a model of factors that influence the adoption and usage of Mobile Money Transfer services in Kenya. The findings in this study provide useful information to Mobile Network Operators that they can use in implementation of their Mobile Money Transfer service. The study was conducted in Juja Township. The study established that the independent variable namely, Performance Expectancy, Effort Expectancy and Social Influence had significant influence on Behavioral Intention towards the use of a given Mobile Money Transfer service. This means that the MMT's users would continue to use a given Mobile Money Transfer service they have chosen. Facilitating Conditions was found to be a significant factor in predicting adoption and use of Mobile Money Transfer for males and females where gender was used as moderating factor. Also Behavioral intention was a significant determinant of Use Behavior of Mobile Money Transfer services. In conclusion the research model was found to be important in determining factors that influence the adoption and use of a given Mobile Money Transfer service.
\end{abstract}

Keywords: Mobile Money Transfer Services (MMT's), Mobile Network Operators (MNO), Structural Equation Model (SEM)

\section{Introduction}

\subsection{Background of the Study}

Mobile Money Transfer services have eased the means of transferring money from one mobile phone user to another. The service has enabled the non banked and banked population to be able to store, send and receive money. MMT's has broken the social and cultural boundaries in money transfer.

The services allow customers to credit their accounts at local authorized agents then they can transfers the money to a different person's phone or redeem it as cash or use the money in paying bills or loan repayment amongst other services. Mobile money systems have created both nonprofessional and professional jobs, such as people working as agents and telecommunication experts employed by mobile network operators.

Currently each of the mobile service providers in Kenya has a mobile money transfer service. Safaricom's M-PESA was the first to be introduced in March 2007, Airtel's, Airtel Money (formerly known as ZAP) was introduced in February 2009, and Orange's.

Orange Money was initiated in November 2010.

Penetration and use of MMT services in Kenya is increasing gradually [14]. Scholarly research about mobile money transfer is generally said to be scarce [15].Therefore there is a need, to understand users' acceptance of mobile Money and to identify the factors affecting their intentions to use Mobile Money Transfer service.

This information can assist MNO's and service providers of Mobile Money Systems in creating services that consumers want to use, or help them discover why potential users avoid using the existing system [19].

\subsection{Statement of the Problem}

In Kenya before the emergence of MMT's, people could send their money through buses or friends. The post office offered a variety of different money transfer products 
including instant money transfer (post pay) and money orders which would be delivered to the post office closest to the recipient [12]. Banks and money transfer companies such as Western Union or Moneygram also offered transfer services, although their outlet or branch networks were not as extensive as the post offices [16].

Introduction of MMT's was more efficient, effective and safe than traditional methods. Safaricom Kenya introduced the first mobile money transfer platform in Kenya M-PESA. Later the other mobile network operators introduced their own platforms. The data of the mobile money transfer services in Kenya Table 1 indicates there is disparity in adoption of different mobile money transfer platforms in Kenya.

Despite the disparity since the introduction of MMT's, the factors which cause the disparity have not been modeled .Therefore this study would model factors influencing adoption and usage of the MMT's in Kenya.

Table 1. Kenya Mobile Money Market Assessment.

\begin{tabular}{lll}
\hline MMT & Mobile Subscribers & Mobile Money Subscribers \\
\hline M-PESA & $17,500,000$ & $15,500,000$ \\
Airtel Money & $3,800,000$ & $2,800,000$ \\
Orange Money & $2,100,000$ & 115,000 \\
Yu Cash & $1,600,000$ & 650,000 \\
\hline
\end{tabular}

Source: Better than cash: Kenya Mobile Money Market Assessment (USAID, 2011)

\subsection{Justification of the Study}

It is important to develop a model that explains factors that influence adoption and usage of MMT's in Kenya. Findings from this study would benefit the MNO's in Kenya by providing useful information that they require in implementation of MMT's. A better understanding of these factors would enable them to develop suitable business models, awareness programs and marketing strategies in order to ensure adoption and continued usage of their services. The research sought to add to the existing body of Knowledge which would be useful for decision making purposes.

\subsection{Objectives}

\subsubsection{General Objective}

To model the factors that influence consumer behavior towards the adoption and usage of Mobile Money transfer services in Kenya.

\subsubsection{Specific Objective}

1. Structural equation modeling of independent variables namely Performance Expectancy, Effort Expectancy, Social Influence and Facilitating Conditions towards use of MMT's.

2. Structural equation modeling in the presence of a moderating effect.

\section{Review of the Previous Studies}

Structural equation modeling has been applied in various fields such as in economics, social sciences and psychology. [20] applied structural equation modeling to investigate the key factors that influence the Ghanian consumers acceptance and use of mobile money transfer technology using key constructs from the Technology Acceptance Model (TAM) and Diffusion of Innovation (DoI) theories. His study established that the results were consistent with key TAM and DoI constructs.

In the study Perceived Ease of Use and Perceived Usefulness were the most significant determinants of Behavioral Intention to use mobile money transfer in Ghana. In his study Perceived Trust, Triability and Personal Risk were found also to significantly affect Behavioral Intention. [19] applied structural equation modeling in investigating factors that affected the Intention to Adopt Internet Banking in Jordan using the Technology Acceptance Model (TAM). The study revealed that, Perceived Usefulness, Perceived Ease of Use and Perceived Trust was important determinant of Behavioral Intention to adopt Internet Banking in Jordan. [2] applied structural equation in testing a conceptual model of oral health.

The study aimed to, test the model in a general population sample using data from the UK adult dental health survey $(\mathrm{N}$ $=5268$ ), the second objective was, to cross-validate these results in two different and diverse samples-edentulous elders $(\mathrm{N}=133)$ and a clinical sample of xerostomia patients $(\mathrm{N}=85)$.

Structural equation modeling indicated support for the model as applied to each of the samples. All of the direct pathways hypothesized by the model were significant, in addition to several indirect or mediated pathways between key variables.

\subsection{Structural Equation Modeling (SEM)}

Structural equation modeling is a term used to describe a large number of statistical models which are used to evaluate validity of substantive theories empirically. Structural equation modeling is an extension of general linear models, path analysis and confirmatory factor analysis.

Linear regression models were the first models that used correlation coefficients and least square criterion to compute regression weights. Creation of a formula to obtain correlation coefficients by Karl Pearson in 1896 provided a relationship index for regression models.

Regression model allows the prediction of dependent observed variables given a set of independent observed variables.

Path analysis model was invented by geneticist Sewall Wright in 1918, Sewall Wright described the path diagram us a pictorial representation of a system of simultaneous equations showing the relation between all variables including disturbances and errors.

Wright proposed a set of rules for writing the equations relating correlations (or covariance's) of variables to the model parameters. Path analysis provided a means to distinguish direct, indirect and total effects of one variable on another. 
Charles Spear man (1927) used correlation coefficient to determine which items correlated or went together to create the factor model, where his basic idea was that if a set of items correlated or went together, individual responses to the set of items could be summed to yield a score that would measure, define or imply a construct.

Spearman was the first to use the term factor analysis in defining a two factor model [18].

The path analysis gained a major boost in social sciences when Keesing (1972), Joreskog (1973) and Wiley (1973) developed very general structural equation models ,which incorporated path diagrams and other features of path analysis into their presentations.

The researchers named these techniques by abbreviation JKW model or commonly known as the LISREL (Linear Structural Relations) model. According to [13] growth curve models could also be incorporated into the structural modeling framework. Flexibility of specifying model allows growth curve modeling to be implemented using SEM. [5] defines Structural equation modeling (SEM) as a statistical methodology that takes a confirmatory (i.e. hypothesis testing) approach to the analysis of structural theory bearing on some phenomenon. The term structural equation modeling illustrates two important aspects of the procedure: First the causal process under study is represented by a series of structural regression equation, and second that these structural relations can be modeled graphically to enable a clearer understanding of theory under study.

The hypothesized model can then be tested statistically in a simultaneous analysis of the entire system of variables to determine the extent to which it is consistent with the data. Goodness of fit is examined if it is adequate then, the model is acceptable. If inadequate then the relations of the model is rejected.

In SEM, ellipses or circles indicates latent variable, rectangle or squares indicating measured variables. Double headed curved arrows indicate covariances between two variables or error terms which indicate non-directionality.

Latent variables are the key variables in structural equation modeling such as in psychological concepts "intelligence" or "attitude".

A structural equation model may include two types of latent variables (endogenous and exogenous). Greek character "Ksi" $(\xi)$ is used to indicate exogenous variables and "eta" $(\eta)$ to indicate endogenous variable. These two types of variables are differentiated based on whether or not they are dependent variables in any system of equations which are represented in the model. Exogenous variables appear as independent variables in all equations, while endogenous variables are dependent variables in at least one equation, although they may be independent variables in other equations in the system.

A general structural equation consists of two parts: Latent variable model and Measurement model. According to [8] structural model contains the following:

The structural model contains exogenous variables indicated by Greek character Ksi $(\xi)$, endogenous latent variable Eta $(\eta)$, Gamma $(\gamma)$ indicates paths connecting $\xi$ to $\eta$ while Beta $(\beta)$ represents paths connecting two endogenous latent variables.

The exogenous variables in SEM are allowed to co-vary freely and the covariance is represented by "Phi" $(\phi)$.

Covariance among the error terms are represented by Psi $(\psi)$. Structural disturbances are indicated by Zeta $(\zeta)$.

Measurement model shows the relations between the manifest (observed variables) and latent variables (unobserved). According to [8] measurement consists of: Variables $\mathrm{X}$ and $\mathrm{Y}$ which represents actual data collected or observations. $\mathrm{X}$ and $\mathrm{Y}$ are measures of exogenous and endogenous variables respectively.

Each X should load onto one $\xi$, and each Y should load onto one $\eta$. The path between an observed variable $\mathrm{X}$ and exogenous variables is indicated by (Lambda X) i.e the item loading on latent variable.

(Lambda Y) represents path between observed variable $\mathrm{Y}$ and endogenous variable. Error terms ("disturbances" for latent variables) are included in the SEM diagram, represented by $\delta$ 's for measured variables and $\varepsilon$ 's for latent variables. The error terms represent residual variances within variables not accounted for by pathways hypothesized in the model.

SEM has special characteristics compared to traditional methods (e.g. linear regression and Confirmatory factor analysis);

First SEM is a multivariate technique which incorporates latent (unobserved) variables and observed variable, while the traditional methods analyzes measured variables only.

SEM solves multiple related equations simultaneously to determine parameters. Secondly it allows graphical (pictorial) representation of the model which is a powerful way to present complex relationships. Third, Structural Equation Modeling specifies error explicitly this indicates it recognizes the imperfect nature of their measures while traditional methods assume measures occurs without errors.

\subsection{Unified Theory of Acceptance and Use of Technology (UTAUT)}

UTAUT (Unified Theory of Acceptance and Use of Technology) figure 1 is a model which was developed and validated by [22]. UTAUT have six constructs: performance expectancy, effort expectancy, social influence, facilitating conditions which are hypothesized to be fundamental determinants of the user behavioral intention of information technology.

According to UTAUT, performance expectancy, effort expectancy, and social influence are hypothesized to influence behavioral intention to use a technology, while behavioral intention and facilitating conditions determine technology use; and that gender, age, experience, and voluntariness of use have moderating effects in the acceptance of information technology. 


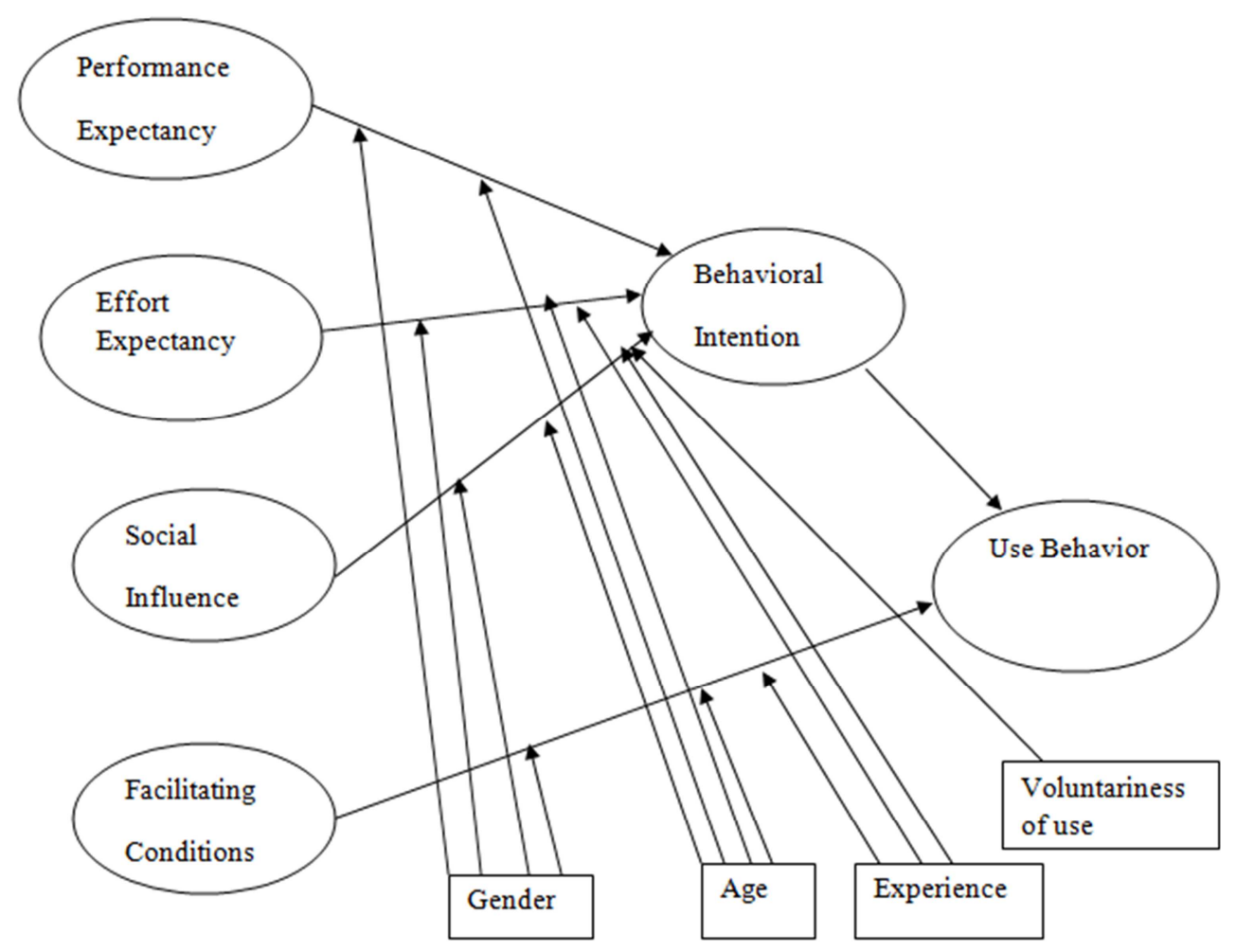

Figure 1. UTAUT model.

\section{Methodology}

The research model for this study is shown in Figure 1. UTAUT (Unified Theory of

Acceptance and Use of Technology) is appropriate model in this study since Mobile Money Transfers services (MMT's) are technological applications.

\subsection{Study Variables}

In this study two variables were used namely exogenous (independent variables) and endogenous variables (are variables which are can be either independent variable in a path as well as a dependent variable).

The exogenous (independent) variable is the research is:

1. Performance Expectancy $\left(\xi_{1}\right)$.

2. Effort Expectancy $\left(\xi_{2}\right)$

3. Social Influence $\left(\xi_{3}\right)$

4. Facilitating Conditions $\left(\xi_{4}\right)$

The endogenous (dependent) variables are:

1. Behavioral Intention $\left(\eta_{1}\right)$.

2. Use Behavior $\left(\eta_{2}\right)$.

Indicators are used to measure independent and dependent variables since they cannot be measured directly. In this study indicators of the independent variables were measured using Likert scale (1-5), ranging from "Strongly disagree" to "Strongly agree".

Indicators (observed variables) of the exogenous (independent) variables are:
$P E 1(X 1)$ I would find the service useful in my job.

$P E 2(X 2)$ Using the service enables me to make transactions more quickly.

$P E 3(X 3)$ Using the service increases my productivity.

$P E 4(X 4)$ Using the service is cheap than others.

$E E 1(X 5)$ my interaction with the service is clear and understandable.

$E E 2(X 6)$ It easy for me to be skillful at using the Mobile Money Transfer service

$E E 3(X 7)$ I find the service easy to use.

$E E 4(X 8)$ Integration of the service with banks is good.

$S I 1(X 9)$ People who influence my behavior think that I should use the service.

$S I 2(X 10)$ People who are important to me think that I should use the service.

$S 13(X 11)$ my friends have been helpful in the use of Mobile Money Transfer service.

$S I 4(X 12)$ in general, many people has supported the use of the Mobile Money Transfer service.

$F C 1(X 13)$ I have the resources necessary to use the system.

$F C 2(X 14)$ the service is most appropriate compared to others.

$F C 3(X 15)$ I have the knowledge necessary to use service.

$F C 4(X 16)$ A specific person (or group) is available for assistance with service difficulties.

Indicators (observed variables) of the endogenous (dependent) variables are:

$B I 1$ ( $Y 1)$ I predict I would use the service in next few days. 
$B I 2(Y 2)$ I plan to use the service next month.

$B I 3(Y 3)$ I intend to use the service in future.

$U B 1$ (Y4) How many times do you use Mobile Money Transfer service during the day?

UB2 (Y5) How many times do you use Mobile Money Transfer service during a week?

UB3 (Y6) How frequently do you use the Mobile Money Transfer service?

From UTAUT, Facilitating Conditions and Behavioral Intention are hypothesized to be the determinants of Use Behavior, and Performance Expectancy, Effort Expectancy, and Social Influence are hypothesized to be the determinants of Behavioral Intention in the context of MMT services.

This study further hypothesizes that the relationships between the determinants and Behavioral Intention/Use Behavior would be moderated by Gender and Age.

Given that the use of MMT services is voluntary, the moderating factors of voluntary and experience are excluded from the research model.

$\lambda_{1 x} \ldots \lambda_{16 x}$ are factor loadings (regression coefficients) between the measured variables and exogenous variables $(\xi \xi)$.

$\lambda_{1 y} \ldots \lambda_{6 y}$ are factor loadings (regression coefficients) between the observed variables and endogenous variables.

Not indicated in the research model are the error terms for the exogenous observed variables $\delta_{1} \ldots \delta_{16}$ and error terms for dependent observed variables $\varepsilon_{1} \ldots \varepsilon_{16}$. $\zeta_{1}$ and $\zeta_{2}$ are latent disturbances ("errors").

Gender and Age are moderating factors for behavior intention/use which are measured without errors.

\subsection{General Structural Equations}

Structural equation modeling can be represented in different frameworks. The general structural equation model can be represented by three matrix equations: The data for SEM are sample covariance and variances obtained from a population (held in $\mathrm{S}$, the observed sample covariance and variance matrix).

$\mathrm{p}$ are the number of indicators of latent endogenous (dependent) variables, $\mathrm{q}$ are the number of indicators of latent exogenous (independent) variables. $m$ is number of endogenous (dependent) variables, $n$ is the number of exogenous(independent) variables. From the research model

Figure 2, $\mathrm{p}=6, \mathrm{q}=16, \mathrm{~m}=2$, and $\mathrm{n}=4$.

$$
\begin{aligned}
& \eta_{(m * 1)}=B_{(m * m)} * \eta_{(m * 1)}+\Gamma_{(m * n)} * \xi_{(n * 1)}+\zeta_{(m * 1)} \\
& \left(\begin{array}{l}
\eta_{1} \\
\eta_{2}
\end{array}\right)=\left(\begin{array}{cc}
0 & 0 \\
\beta_{21} & 0
\end{array}\right) *\left(\begin{array}{l}
\eta_{1} \\
\eta_{2}
\end{array}\right)+\left(\begin{array}{cccc}
\gamma_{11} & \gamma_{12} \gamma_{13} & 0 \\
0 & 0 & 0 & \gamma_{24}
\end{array}\right) *\left(\begin{array}{l}
\xi_{1} \\
\xi_{2} \\
\xi_{3} \\
\xi_{4}
\end{array}\right)+\left(\begin{array}{l}
\zeta_{1} \\
\zeta_{2}
\end{array}\right)
\end{aligned}
$$

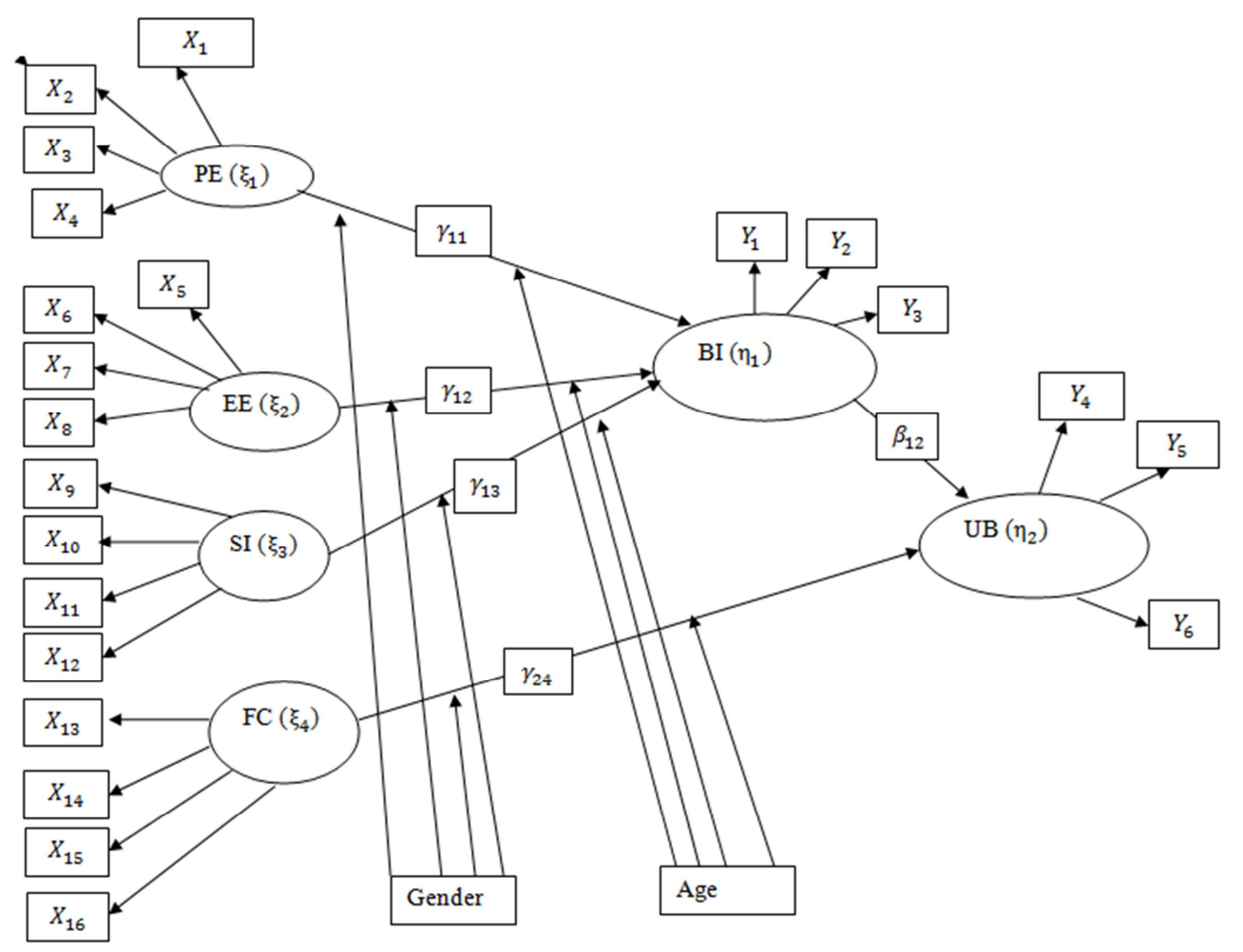

Figure 2. Research model.

Equation 1 is the general representation of the model relating latent variables. Where

$\eta_{(m * 1)}$ is the vector of the latent endogenous variables, $B_{(m * m)}$ is a matrix of structural parameters relating latent endogenous variables $\Gamma_{(m * n)}$ is a matrix of structural parameters relating latent endogenous to exogenous variables, $\xi_{(n * 1)}$ is a vector of latent exogenous variables and $\zeta_{(m * 1)}$ are latent endogenous variable structural disturbances (errors in equations). 


$$
\begin{gathered}
Y_{(P * 1)}=\Lambda_{y(p * m)} * \eta_{(m * 1)}+\varepsilon_{(P * 1)} \\
\left(\begin{array}{c}
X_{1} \\
X_{2} \\
\vdots \\
X_{16}
\end{array}\right)=\left(\begin{array}{cccc}
\lambda_{11 \mathrm{x}} & 0 & 0 & 0 \\
0 & \lambda_{21 \mathrm{x}} 0 & 0 \\
\cdot & \cdot & \cdot & \cdot \\
\vdots & \vdots & \vdots & \vdots \\
0 & 0 & 0 & \lambda_{16 x}
\end{array}\right) *\left(\begin{array}{c}
\xi_{1} \\
\xi_{2} \\
\xi_{3} \\
\xi_{4}
\end{array}\right)+\left(\begin{array}{c}
\delta_{1} \\
\delta_{2} \\
\vdots \\
\delta_{16}
\end{array}\right)
\end{gathered}
$$

Equation 3 is the matrix representation of the measurement model relating the observed variable and endogenous (dependent) variable. Where $Y_{(P * 1)}$ represents indicators of latent endogenous variables, $\Lambda_{y(p * m)}$ is a matrix of regression coefficients relating indicators to latent variables, $\eta_{(m * 1)}$ is the vector of the latent endogenous variables, $\varepsilon_{(P * 1)}$ is a vector of measurement errors in endogenous indicators.

$$
\begin{gathered}
X_{(q * 1)}=\Lambda_{x(q * n)} * \xi_{(n * 1)}+\delta_{(q * 1)} \\
\left(\begin{array}{c}
Y_{1} \\
Y_{2} \\
Y_{3} \\
Y_{4} \\
Y_{5} \\
Y_{6}
\end{array}\right)=\left(\begin{array}{cc}
\lambda_{11 y} & 0 \\
\lambda_{12 y} & 0 \\
\lambda_{13 y} & 0 \\
0 & \lambda_{21 y} \\
0 & \lambda_{22 y} \\
0 & \lambda_{23 y}
\end{array}\right) *\left(\begin{array}{l}
\eta_{1} \\
\eta_{2}
\end{array}\right)+\left(\begin{array}{c} 
\\
\varepsilon_{1} \\
\varepsilon_{2} \\
\varepsilon_{3} \\
\varepsilon_{4} \\
\varepsilon_{5} \\
\varepsilon_{6}
\end{array}\right)
\end{gathered}
$$

Equation 5 is a matrix representation of the measurement model relating the observed variable and exogenous (independent) variables. Where $X_{(q * 1)}$ is a vector of indicators of latent exogenous variables, $\Lambda_{x(q * n)}$ is a matrix of regression coefficients relating measured variables and latent dependent variables, $\xi_{(n * 1)}$ is a vector of latent exogenous variables and $\delta_{(q * 1)}$ is a vector of measurement errors in exogenous indicators.

For model specification to be complete the following covariance's matrices are defined.

$\varepsilon$ 's are assumed to be uncorrelated among themselves and with $\eta, \xi$ and $\zeta$. Also it is assumed that the $\delta$ 's are uncorrelated among themselves and with $\eta, \xi$ and $\zeta$.

$$
S_{(p+q \times p+q)}=\left(\begin{array}{ccc}
S_{11} & \cdots & \\
\vdots & \ddots & \vdots \\
S_{22,1} & \cdots & S_{22,22}
\end{array}\right)
$$

Where $S_{(p+q \times p+q)}$ is the covariance matrix among observed (indicator) variables.

$$
(\mathrm{Phi}) \Phi_{(n \times n)}=\left(\begin{array}{cccc} 
& & & \\
\Phi_{2,1} & 1 & & \\
\Phi_{3,1} & \Phi_{3,2} & 1 & \\
\Phi_{4,1} & \Phi_{4,2} & \Phi_{4,3} & 1
\end{array}\right)
$$

$\Phi_{(n \times n)}$ is a matrix of covariance among latent exogenous variables

$$
(P s i) \Psi_{(m \times m)}=\left(\begin{array}{cc}
\Psi_{11} & 0 \\
0 & \Psi_{22}
\end{array}\right)
$$

$\Psi_{(m \times m)}$ is a matrix of covariance among structural disturbances.

$$
(\text { Theta }) \Theta_{(p \times p)}=\left(\begin{array}{ccc}
\Theta_{\varepsilon 1 \varepsilon 1} & \cdots & 0 \\
\vdots & \ddots & \vdots \\
0 & \cdots & \Theta_{\varepsilon 6 \varepsilon 6}
\end{array}\right)
$$

$\Theta_{(p \times p)}$ is the covariance matrix among measurement errors for endogenous variables.

$$
(\text { Theta }) \Theta_{(q \times q)}=\left(\begin{array}{ccc}
\Theta_{\delta 1 \delta 1} & \cdots & 0 \\
\vdots & \ddots & \vdots \\
0 & \cdots & \Theta_{\delta 16 \delta 16}
\end{array}\right)
$$

$\Theta_{(q \times q)}$ is covariance matrix among measurement errors for exogenous variables.

\subsection{Estimation of Model Parameters}

The goal of estimation is to produce an implied population matrix $\Sigma(\theta)$ such that the parameter values yield a matrix close as possible to $\mathrm{S}$ which is the sample covariance matrix of the observed variables, with the residual matrix (the difference between $\mathrm{S}$ and $\Sigma(\theta)$ ) being minimized. The implied covariance matrix is given as $\Sigma(\theta)$ where $\theta$ is the vector that contains the regression coefficient, variances and covariance's parameters that are part of the model specified by the researcher. The SEM implied covariance matrix is given as follows:

$$
\Sigma(\theta)=\left[\begin{array}{cc}
\Sigma_{Y Y} & \Sigma_{Y X} \\
\Sigma_{X Y} & \Sigma_{X X}
\end{array}\right]
$$

Where

$$
\begin{gathered}
\Sigma_{Y Y}=\Lambda_{Y}(I-B)^{-1}\left(\Gamma \Phi \Gamma^{\prime}+\psi\right)\left[(I-B)^{-1}\right]^{\prime} \Lambda_{Y}+\Theta_{e} \\
\Sigma_{X Y}=\Lambda_{X} \Phi \Gamma^{\prime}\left[(I-B)^{-1}\right]^{\prime} \Lambda_{Y} \\
\Sigma_{Y X}=\Lambda_{Y}(I-B)^{-1}\left(\Gamma \Phi \Lambda_{X}^{\prime}\right) \\
\Sigma_{X X}=\Lambda_{X} \Phi \Lambda_{X}^{\prime}+\Theta_{\delta}
\end{gathered}
$$

$I$ is an identity matrix, all the symbols are as defined in equations above.

$\Sigma(\theta)$ can be generated using various methods. The method to be used is guided by characteristics of the data including sample size and distribution of the data.

One of the methods is Generalized Least Squares (GLS). According to [18], GLS method has required asymptotic properties-that is large sample properties, such as minimum variance and unbiasedness. Also GLS estimation method assumes multivariate normality of the observed variables. The best estimates are obtained based on minimization of a fitting function; SEM program compares the original sample covariance matrix of the observed variables with the implied population covariance matrix of the specified model.

The objective is to obtain an implied matrix that is as close to the original covariance matrix as possible. Whatever function is chosen, the desired result of the estimation process is to obtain a fitting function that is close to 0 . A fitting function score of 0 implies that the model's estimated covariance matrix and the original sample covariance matrix are equal. 


\subsection{Generalized Least Squares (GLS)}

In this study Generalized Least Squares (GLS) estimation method was used. The general form of the minimization fit function is:

$$
Q=(S-\Sigma(\theta))^{\prime} W(S-\Sigma(\theta))
$$

Where, $S=$ vector containing the variances and covariance's of the observed variables,

$\Sigma(\theta)=$ vector containing corresponding variances and covariance's as predicted by the model, $W=$ weight matrix.

The weight matrix, $W$, in the function above, corresponds to the estimation method chosen. W is chosen to minimize $\mathrm{Q}$, and $\mathrm{Q}(\mathrm{N}-1)$ gives the fitting function, in most cases a ChiSquare distributed statistic.

$$
F_{G L S}=1 / 2 \operatorname{tr}\left[\left([S-\Sigma(\theta)] W^{-1}\right)^{2}\right]
$$

Where, $t r=$ trace operator, takes sum of elements on main diagonal of matrix. $W^{-1}=$ optimal weight matrix, must be selected by researcher (most common choice is $S^{-1}$ ).

\subsection{Multiple Group Analysis}

Multiple sample/group analysis is implemented in Structural Equation Modeling by observing the parameter estimates of the same model obtained from different samples or groups. Moderating variable, gender and age was used to perform a multiple-group analysis.

This can be achieved by constraining any or several of the paths say, $\gamma, \beta, \lambda_{X}, \lambda_{Y}$ in the second model to be equal to those in the first model [8].

\subsection{Significance of Parameter Estimates}

According to [21], in SEM the null hypothesis is same as in regression; the path coefficients are hypothesized to be equal to zero.

If the path coefficients are found to be greater than zero then there is significant support for the hypothesized relationship in the model. The parameter estimates are evaluated with z-test (the parameter estimates divided by the estimated standard error) and a p-value obtained at a given significance level say 0.05 or 0.01 .

\subsection{Model Fit Indices}

According to [11] absolute fit indices unlike incremental fit indices, their calculations does not rely on comparison with a baseline model but is a measure of how well the model fits in comparison to no model at all.

The following Absolute fit indices are included in this category, Chi-square Test, Root Mean Square Error of Approximation (RMSEA), Standardized Root Mean Square residual (SRMR).

\subsubsection{Model Chi-square $\left(\chi^{2}\right)$}

Chi-square value is used as the traditional measure for examining the fit of the overall model. A model is good if it produces insignificant results at 0.05 thresholds [3].
Large samples increase the quantity of Chi-square, indicating that it is highly related to the volume of the sample. Measure of fit can be used to examine overall model with

$$
\text { Measure of Fit }=\chi^{2} / d f
$$

$\mathrm{df}($ degrees of freedom $)=t(t-1) / 2$ where $t$ is the number of observed variables.

\subsubsection{Root Mean Square Error of Approximation (RMSEA)}

The RMSEA is a measure of how well the model, with unknown but optimally chosen parameter estimates would fit the population's covariance matrix [5].

Root Mean Square Error of Approximation (RMSEA) is related to residual in the model.

RMSEA values range from 0 to 1 with a smaller RMSEA value indicating better model fit.

A RMSEA value of 0.06 or less indicates an acceptable model fit [10]. RMSEA is calculated using the following formula

$$
R M S E A=\sqrt{\frac{\left(\chi^{2}-d f\right)}{d f(N-1)}}
$$

$\mathrm{df}($ degrees of freedom $)=t(t-1) / 2$ where $t$ is the number of observed variables.

\subsubsection{Standardized Root Mean Square Residual (SRMR)}

SRMR values range from zero to 1 with well fitting models having values less than .05

[9] however values as high as 0.08 are deemed acceptable [10]. An SRMR of 0 indicates a perfect fit however the SRMR value may be lower if the parameters of the model are many and also in large sample size models [9].

$$
S R M R=\sqrt{\frac{\left\{2 \sum_{i=1}^{t} \Sigma_{j=1}^{q}\left[\frac{s_{\mathrm{ij}}-\Sigma(\theta)}{s_{\mathrm{ii}} \mathrm{s}_{\mathrm{jj}}}\right]^{2}\right\}}{t(t+1)}}
$$

Where $s_{i i}$ and $s_{j j}$ are observed variables standard deviations, $s_{\mathrm{ij}}=$ observed variables

Covariance's, $\Sigma(\theta)=$ implied covariance's and $\mathrm{t}=$ number of the observed variables.

\subsection{Sample Size}

SEM is based on covariance and covariance is less stable when estimated from small samples. Thus generally SEM is a large sample technique. Chi-square tests and parameter estimates are also sensitive to sample size. According to [21] if the models variables are highly reliable it may be possible to estimate models with smaller sample sizes.

\subsection{Sampling Frame and Sampling Technique}

The data was collected in Juja township, Kalimoni sub- 
county (Population size $=19861$ ) in the following places (Muchatha, Gachororo, Jomo Kenyatta University of Agriculture and Technology (JKUAT)).

A structured questionnaire containing different questions on each latent variable was used. Simple random sampling method was used to administer the questionnaire to the respondents. The respondents were briefed about the study, and then they were requested to tick the response that best describe their level of agreement with statements.

The items used to measure performance expectancy, effort expectancy; social influence, facilitating conditions, and behavioral intention were adapted from [22].

Pre-testing of the measures was conducted by carrying out a pilot study then adjustment was made accordingly.

The sample size was calculated using the formula proposed by [23].

$$
n=\frac{N}{1+N(e)^{2}}
$$

Where $\mathrm{n}=$ sample size, $\mathrm{N}=$ population size, $\mathrm{e}$ is the level of precision, $\mathrm{N}=19,861, \mathrm{e}=0.05$ with confidence interval of $95 \%$.

$$
n=\frac{19861}{1+19861(0.05)^{2}}=392.103
$$

\section{Results and Discussion}

Data in this study was analyzed using lavaan (latent variable analysis) package [17] in R statistical programming language. The packages contain functions for fitting general linear structural equation models with observed and unobserved variables. The study findings were presented based on each specific objective.

\subsection{Characteristics of the Respondents}

Table 2 shows the characteristics of the respondent's distribution of Gender, Education level and the Mobile Money Transfer service they use represented in percentage.

The findings in Table 2 indicates that majority of the respondents $248(66.7 \%)$ in the study were male while 124 $(33.3 \%)$ were females.

The research findings also indicated that majority of the respondents $320(86 \%)$ were in 18-35 years age bracket; while $52(14 \%)$ of the respondents had 36 years and above.

From the study findings majority of the respondents 206 (55.4\%) had attained university education, 98 (26.4\%) of the respondent had attained secondary education; $44(11.8 \%)$ of the respondents had attained a diploma while, $24(6.4 \%)$ of the respondents had attained primary education.

The study findings indicated that majority of the respondents $334(89.8 \%)$ use Safaricom's M-PESA in money transfer; $28(7.5 \%)$ of the respondents indicated that they use both MPESA and Airtel Money services in money transfer; 6 $(1.6 \%)$ of the respondents indicated that they use Airtel Money in money transfer while, $4(1.1 \%)$ of the respondents indicated they use Orange Money in money transfer.
Table 2. Characteristics of the respondents.

\begin{tabular}{l|ll}
\hline Characteristic & Frequency & Percent \\
\hline Gender & & \\
Male & 248 & 66.7 \\
Female & 124 & 33.3 \\
Total & 372 & 100 \\
Age & & \\
18-35 years & 320 & 86.0 \\
36 years and above & 52 & 14.0 \\
Total & 372 & 100 \\
Education Level & & \\
Primary & 24 & 6.4 \\
Secondary & 98 & 26.4 \\
Diploma & 44 & 11.8 \\
Degree & 206 & 55.4 \\
Total & 372 & 100 \\
Mobile Money Transfer & & \\
Airtel Money & 6 & 1.6 \\
M-PESA & 334 & 89.8 \\
Orange Money & 4 & 1.1 \\
M-PESA and Airtel Money & 28 & \\
Total & 372 & \\
\hline & & \\
\hline & 6.5 & \\
\hline & & \\
\hline
\end{tabular}

\subsection{Observed Variables Loadings to Latent Variables}

Where PE is (Performance Expectancy), EE is (Effort Expectancy), FC is (Facilitating

Conditions), $\mathrm{BI}$ is (Behavioral Intention), and $\mathrm{UB}$ is (Use Behavior).

The operator $=\sim$, between latent variables and observed variables means (measured by).

Factor loadings were obtained between the latent variables and the observed measurements variables as indicated in Table 3. All the observed variables were significant in explaining the latent variables as indicated by (P-values $<0.05$ level of significance). This implied that the observed variables which were used to measure the independent variables at a 5 points Likert scale ranging from "Strongly disagree" to "Strongly agree" are appropriate in explaining the model factors. That is the observed variables $P E 1, P E 2$, and $P E 3$ as stated in study variables are appropriate in explaining Performance Expectancy (PE), the observed variables EE1, EE2, EE3 and $E E 4$ as stated in study variables are appropriate in explaining Effort Expectancy (EE).

The observed variables SI1, SI2, SI3 and SI4 as stated in study variables are appropriate in describing Social Influence (SI). The observed variables $F C 1, F C 2, F C 3$ and $F C 4$ are appropriate in explaining Facilitating Conditions (FC).

The observed variables $B I 1$ and $B I 2$ as stated in study variables are appropriate is explaining Behavioral Intention (BI). The observed variables $U B 1, U B 2$, and $U B 3$ as stated in study variables are appropriate in explaining Use Behavior (UB) in context of Mobile Money Transfer Services.

The factor loadings without the p-values were fixed in structural equation model therefore their standard errors were 
not calculated as well as their z-values.

Table 3. Observed variables loadings to latent variables.

\begin{tabular}{|c|c|c|c|c|}
\hline $\begin{array}{l}\text { Latent } \\
\text { Variables }\end{array}$ & Parameter Estimates & Std. Error & Z-value & P-value \\
\hline $\mathrm{PE}=\sim \mathrm{PE} 1$ & 0.629 & & & \\
\hline $\mathrm{PE}=\sim \mathrm{PE} 2$ & 0.764 & 0.226 & 5.966 & 0.000 \\
\hline $\mathrm{PE}=\sim \mathrm{PE} 3$ & 0.422 & 0.169 & 5.352 & 0.000 \\
\hline $\mathrm{EE}=\sim \mathrm{EE} 1$ & 0.577 & & & \\
\hline $\mathrm{EE}=\sim \mathrm{EE} 2$ & 0.672 & 0.157 & 7.077 & 0.000 \\
\hline $\mathrm{EE}=\sim \mathrm{EE} 3$ & 0.516 & 0.111 & 6.206 & 0.000 \\
\hline $\mathrm{EE}=\sim \mathrm{EE} 4$ & 0.430 & 0.151 & 5.322 & 0.000 \\
\hline $\mathrm{SI}=\sim \mathrm{SI} 2$ & 0.723 & & & \\
\hline $\mathrm{SI}=\sim \mathrm{SI} 3$ & 0.740 & 0.095 & 9.251 & 0.000 \\
\hline $\mathrm{SI}=\sim \mathrm{SI} 4$ & 0.442 & 0.070 & 6.806 & 0.000 \\
\hline $\mathrm{SI}=\sim \mathrm{SI} 1$ & 0.709 & 0.109 & 10.244 & 0.000 \\
\hline $\mathrm{FC}=\sim \mathrm{FC} 1$ & 0.746 & & & \\
\hline $\mathrm{FC}=\sim \mathrm{FC} 2$ & 0.841 & 0.075 & 15.288 & 0.000 \\
\hline $\mathrm{FC}=\sim \mathrm{FC} 3$ & 0.926 & 0.079 & 15.188 & 0.000 \\
\hline $\mathrm{FC}=\sim \mathrm{FC} 4$ & 0.832 & 0.075 & 14.600 & 0.000 \\
\hline $\mathrm{BI}=\sim \mathrm{BI} 1$ & 0.870 & & & \\
\hline $\mathrm{BI}=\sim \mathrm{BI} 2$ & 0.622 & 0.104 & 6.072 & 0.000 \\
\hline $\mathrm{UB}=\sim \mathrm{UB} 1$ & 0.746 & & & \\
\hline $\mathrm{UB}=\sim \mathrm{UB} 2$ & 0.974 & 0.107 & 12.591 & 0.000 \\
\hline $\mathrm{UB}=\sim \mathrm{UB} 3$ & 0.658 & 0.107 & 11.675 & 0.000 \\
\hline
\end{tabular}

\subsection{Structural Equation Model for the Study}

The first specific objective was to obtain Structural equation model of independent variables namely performance expectancy, effort expectancy, social influence and facilitating conditions towards use of MMT's. The model parameters are represented in Table 4.

Table 4. Model parameters.

\begin{tabular}{lllll}
\hline Regression & Parameter Estimates & Std. Error & Z-value & P-value \\
\hline BI PE & -0.688 & 0.220 & -3.131 & 0.002 \\
BI $\sim$ EE & 0.877 & 0.228 & 3.852 & 0.000 \\
BI SI & 0.261 & 0.131 & 1.995 & 0.040 \\
UB $\sim$ BI & 0.101 & 0.035 & 2.918 & 0.004 \\
UB $\sim$ FC & -0.001 & 0.046 & -0.020 & 0.980 \\
\hline
\end{tabular}

The symbol, " $\sim$ " means one variable is regressed on the other variable. The following were the model parameters of the structural equations.

Where BI is (Behavioral Intention), PE is (Performance Expectancy), EE is (Effort

Expectancy), FC is (Facilitating Conditions) and UB is (Use Behavior).

In this study, significance of parameter was evaluated at 0.05 , significance level. A parameter estimate was significant if the probability value (P-value) was less than 0.05 level of significance, while a parameter was insignificant if the probability value (P-value) was greater than 0.05 .

Parameter estimate between Performance Expectancy and Behavioral Intention (-0.688) was significant with $(\mathrm{P}=0.002<0.05)$. Parameter estimate between Effort Expectancy and Behavioral Intention (0.878) was significant with $(\mathrm{P}=0.001<0.05)$. Parameter estimate between Social Influence and Behavioral Intention (0.261) was significant with $(\mathrm{P}=0.04<0.05)$.

Estimate between Behavioral Intention and Use Behavior with a value of $(0.101)$ was significant with $(\mathrm{P}=0.004<0.05)$. From the model the parameter estimate for the path connecting Facilitating Conditions and Use Behavior is ($0.001)$ was not significant with a $(\mathrm{P}=0.980>0.05)$. The structural model relating independent latent variables and dependent latent variables was represented by the following equations.

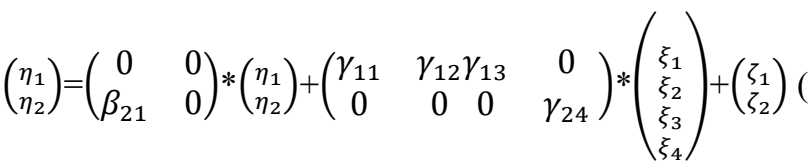

$$
\begin{aligned}
& \left(\begin{array}{l}
\eta_{1} \\
\eta_{2}
\end{array}\right)=\left(\begin{array}{cc}
0 & 0 \\
0.101 & 0
\end{array}\right) *\left(\begin{array}{l}
\eta_{1} \\
\eta_{2}
\end{array}\right)+ \\
& \left(\begin{array}{cccc}
-0.688 & 0.877 & 0.261 & 0 \\
0 & 0 & 0 & -0.001
\end{array}\right) *\left(\begin{array}{l}
\xi_{1} \\
\xi_{2} \\
\xi_{3} \\
\xi_{4}
\end{array}\right)+\left(\begin{array}{l}
\zeta_{1} \\
\zeta_{2}
\end{array}\right)(21) \\
& \left(\begin{array}{l}
\eta_{1} \\
\eta_{2}
\end{array}\right)=\left(\begin{array}{c}
0 \\
0.101 \beta_{21}
\end{array}\right)+\left(\begin{array}{c}
-0.688 \xi_{1}+0.877 \xi_{2}+0.261 \xi_{3} \\
-0.001 \xi_{4}
\end{array}\right)+\left(\begin{array}{l}
\zeta_{1} \\
\zeta_{2}
\end{array}\right) \\
& \left(\begin{array}{l}
\eta_{1} \\
\eta_{2}
\end{array}\right)=\left(\begin{array}{c}
-0.688 \xi_{1}+0.877 \xi_{2}+0.261 \xi_{3}+\zeta_{1} \\
0.101 \beta_{21}-0.001 \xi_{4}+\zeta_{2}
\end{array}\right)
\end{aligned}
$$

Equation 23 is a matrix representation of model relating latent variables. Where $\eta_{1}$ and $\eta_{2}$ are the latent endogenous variables, $\xi_{1}, \xi_{2}, \xi_{3}$ and $\xi_{4}$ are latent exogenous variables.

$\zeta_{1}$ and $\zeta_{2}$ are the structural errors. From the model represented in equation 23, the results indicates that a unit increase of Performance Expectancy would lead to (-) 0.688 increase in Behavioral Intention, but the negative sign is a contradiction while a factor is significant in this case therefore further research can be done to find out why. A unit increase in Effort Expectancy would lead to 0.877 increases in Behavioral Intention and a unit increase in Social Influence would lead to, 0.261 increase in Behavioral Intention to use a given Mobile Money Transfer Service. Moreover, a unit increase in Behavioral Intention would lead to 0.101 increase in Use Behavior of a given Mobile Money Transfer Service.

Figure 3 is a pictorial representation of the overall model indicating the paths connecting the exogenous variables (Performance Expectancy, Effort Expectancy, Social Influence and Facilitating Conditions), and the endogenous variables (Behavioral Intention and Use Behavior). 


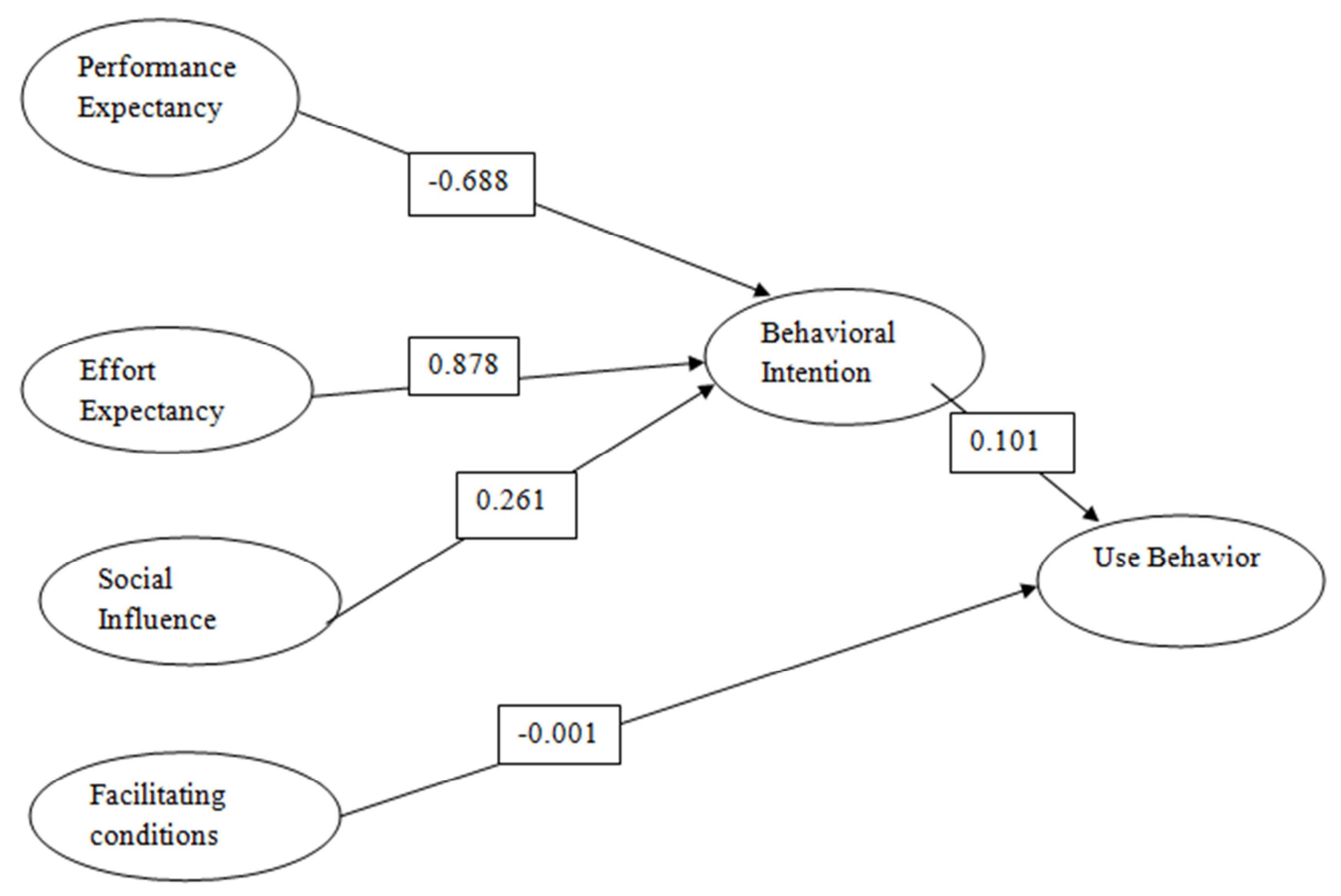

Figure 3. Model parameters.

\subsection{Overall Model Fit Test}

Structural model was used to determine whether the data fits the theoretical model. The following model fit indices was used to determine the overall model fit.

Table 5. Model fit indices.

\begin{tabular}{|c|c|c|}
\hline Fit indices & Value & $\begin{array}{l}\text { Recommended } \\
\text { value }\end{array}$ \\
\hline Measure of Fit $=\chi^{2} / d f$ & $352.628 / 159=2.22$ & $\leq 3$ \\
\hline $\begin{array}{l}\text { Root Mean Square of Error of } \\
\text { Approximation (RMSEA) }\end{array}$ & 0.05 & 0.06 or less \\
\hline $\begin{array}{l}\text { Standard Root Mean Square of } \\
\text { Residuals (SRMR) }\end{array}$ & 0.08 & 0.08 \\
\hline
\end{tabular}

From the Table 5, The Measure of fit $=\chi^{2} / d f=2.22$ which was less than the recommended value of 3 [6] indicating a well-fitting model. The Root Mean

Square of Error of Approximation (RMSEA) of the model is $(0.057)$ indicating a well fitting model. The recommended value for Root Mean Square of Error of Approximation (RMSEA) is 0.06 or less [10].

The Standard Root Mean Square of Residuals (SRMR) value of the model is (0.08), the recommended value for Standard

Root Mean Square of Residuals (SRMR) is value as high as 0.08 [10].

\subsection{Structural Equation Model in the Presence of a Moderating Effect}

The second specific objective was to model the moderating effect of gender and age on use of Mobile Money Transfer services.

Multiple group analysis was conducted to determine the moderating effect of gender and age on the structural equation model. Multiple group analysis was implemented in

Structural Equation Modeling by observing the parameter estimates of the same model obtained from different groups.

In this study a multiple group analysis was conducted by observing the regression parameter estimates of males and female from moderating variable; gender.

Moderating effect of age was not determined since the second group (36 years and above) had a very small sample size of 52. Therefore a structural equation model was not obtained. Meaning age had no moderating effect on factors that influences adoption and usage of Mobile Money Transfer services in the study.

\subsubsection{Structural Equation Model for Male Moderation}

Table 6. Parameter estimates for male moderation.

\begin{tabular}{lllll}
\hline Regression & Parameter Estimates & Std. Error & Z-value & P-value \\
\hline BI $\sim$ PE & -0.299 & 0.212 & -1.495 & 0.162 \\
BI EE & 0.671 & 0.209 & 3.253 & 0.001 \\
BI SI & 0.381 & 0.127 & 3.071 & 0.002 \\
UB $\sim$ BI & 0.132 & 0.054 & 2.537 & 0.011 \\
UB $\sim$ FC & -0.241 & 0.066 & -3.470 & 0.001 \\
\hline
\end{tabular}

Where BI is (Behavioral Intention), PE is (Performance Expectancy), EE is (Effort Expectancy), FC is (Facilitating Conditions) and UB is (Use Behavior).

The Findings in Table 6 indicates that Performance Expectancy in Male was not a Significant Factor as shown by 
$(\mathrm{P}=0.162>0.05$ level of significance $)$.

Effort Expectancy was a significant factor in determining Behavioral Intention for male as indicated by $(\mathrm{P}=0.001<0.05)$. Social Influence was a significant factor for male in determining Behavioral Intention to use a given Mobile Money Transfer services indicated by $(\mathrm{P}=0.002<0.05)$. Behavioral Intention was a significant factor in determining

Use Behavior of a given Mobile Money Transfer Services indicated by $(\mathrm{P}=0.011<0.05)$.

Facilitating Conditions was a significant factor in determining Use Behavior of a given Mobile Money Transfer Services as indicated by $(\mathrm{P}=0.001<0.05)$. The structural model relating independent latent variables and dependent latent variables is represented by the following equations.

$$
\begin{aligned}
& \left(\begin{array}{l}
\eta_{1} \\
\eta_{2}
\end{array}\right)=\left(\begin{array}{cc}
0 & 0 \\
0.132 & 0
\end{array}\right) *\left(\begin{array}{l}
\eta_{1} \\
\eta_{2}
\end{array}\right)+ \\
& \left(\begin{array}{cccc}
-0.299 & 0.671 & 0.381 & 0 \\
0 & 0 & 0 & -0.241
\end{array}\right) *\left(\begin{array}{l}
\xi_{1} \\
\xi_{2} \\
\xi_{3} \\
\xi_{4}
\end{array}\right)+\left(\begin{array}{l}
\zeta_{1} \\
\zeta_{2}
\end{array}\right) \\
& \left(\begin{array}{l}
\eta_{1} \\
\eta_{2}
\end{array}\right)=\left(\begin{array}{c}
0 \\
0.132 \eta_{2}
\end{array}\right)+\left(\begin{array}{c}
-0.299 \xi_{1}+0.671 \xi_{2}+0.381 \xi_{3} \\
-0.2411 \xi_{4}
\end{array}\right)+\left(\begin{array}{l}
\zeta_{1} \\
\zeta_{2}
\end{array}\right) \\
& \left(\begin{array}{l}
\eta_{1} \\
\eta_{2}
\end{array}\right)=\left(\begin{array}{c}
-0.299 \xi_{1}+0.671 \xi_{2}+0.381 \xi_{3}+\zeta_{1} \\
0.132 \eta_{2}-0.241 \xi_{4}+\zeta_{2}
\end{array}\right)
\end{aligned}
$$

Equation 27 is the matrix representation of the model relating latent variables for male's respondents in the study. Where $\eta_{1}$ and $\eta_{2}$ are the latent endogenous variables, $\xi_{1}, \xi_{2}$, $\xi_{3}$ and $\xi_{4}$ are latent exogenous variables.

$\zeta_{1}$ and $\zeta_{2}$ are the structural errors.

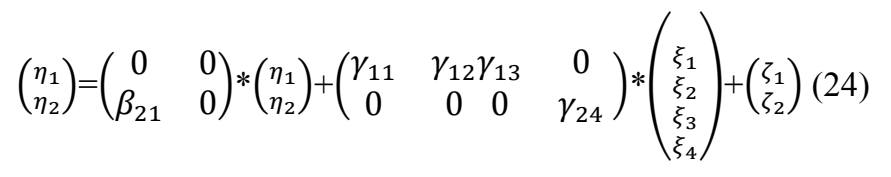

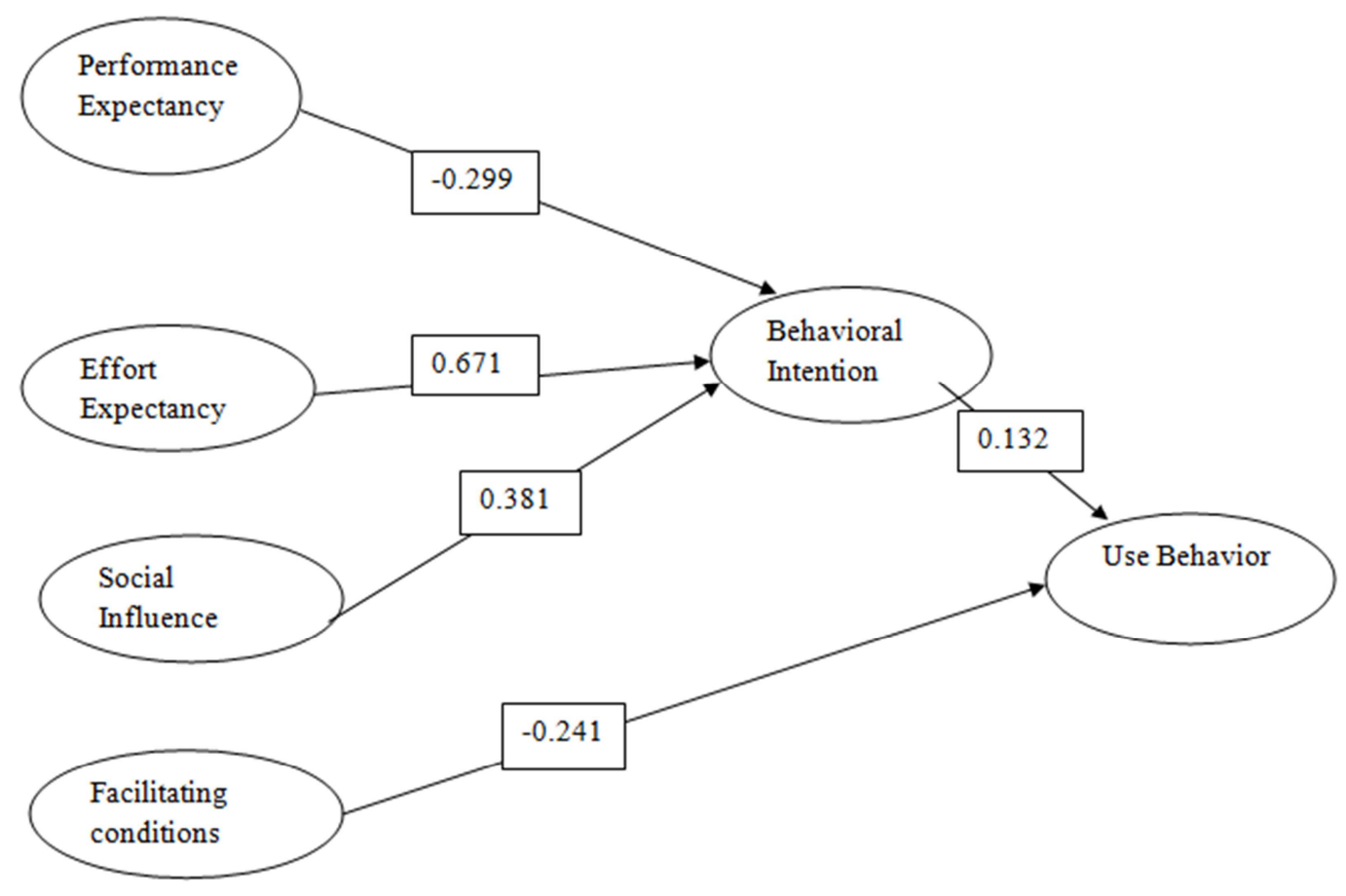

Figure 4. Diagram for male moderation.

Figure 4 is a pictorial representation of the structural equation model indicating the paths connecting the exogenous variables (Performance Expectancy, Effort Expectancy, Social Influence and Facilitating Conditions), and the endogenous variables (Behavioral Intention and Use Behavior) for male moderation.

\subsubsection{Structural Model for Female Moderation}

Where BI is (Behavioral Intention), PE is (Performance Expectancy), EE is (Effort Expectancy), FC is (Facilitating Conditions) and UB is (Use Behavior).

The Findings in Table 7 indicates that Performance Expectancy in Female was not a Significant Factor as shown by $(\mathrm{P}$-value $=0.637>0.05$ level of significance $)$.

Table 7. Parameter estimates for female moderation.

\begin{tabular}{lllll}
\hline Regression & $\begin{array}{l}\text { Parameter } \\
\text { Estimates }\end{array}$ & Std. Errors & Z-value & P-value \\
\hline BI $\sim$ PE & -0.270 & 0.576 & -0.557 & 0.637 \\
BI $\sim$ EE & 1.975 & 1.312 & 1.571 & 0.192 \\
BI $\sim$ SI & -0.365 & 0.641 & -0.398 & 0.670 \\
UB $\sim$ BI & 0.244 & 0.101 & 2.222 & 0.022 \\
UB $\sim$ FC & 0.156 & 0.081 & 2.060 & 0.041 \\
\hline
\end{tabular}

Effort Expectancy was not a significant factor in determining Behavioral Intention for Female indicated by 
$(\mathrm{P}=0.192>0.05)$. Social Influence was not a significant factor for Female in determining Behavioral Intention to use a given Mobile Money Transfer services indicated by $(\mathrm{P}=0.670>0.05)$. Behavioral Intention was a significant factor in determining Use Behavior of a given Mobile Money Transfer Services indicated by $(\mathrm{P}=0.022<0.05)$.

Facilitating Conditions was a significant factor in determining Use Behavior of a given Mobile Money Transfer Services as indicated by $(\mathrm{P}=0.041<0.05$ level of significance). The structural model relating independent latent variables and dependent latent variables is represented by the following equations.

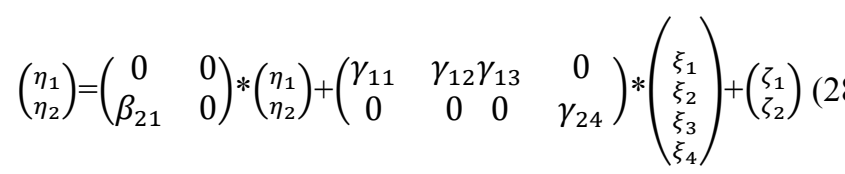

$$
\begin{aligned}
& \left(\begin{array}{l}
\eta_{1} \\
\eta_{2}
\end{array}\right)=\left(\begin{array}{cc}
0 & 0 \\
0.244 & 0
\end{array}\right) *\left(\begin{array}{l}
\eta_{1} \\
\eta_{2}
\end{array}\right)+ \\
& \left(\begin{array}{cccc}
-0.270 & 1.975 & -0.365 & 0 \\
0 & 0 & 0 & 0.156
\end{array}\right) *\left(\begin{array}{l}
\xi_{1} \\
\xi_{2} \\
\xi_{3} \\
\xi_{4}
\end{array}\right)+\left(\begin{array}{l}
\zeta_{1} \\
\zeta_{2}
\end{array}\right) \\
& \left(\begin{array}{l}
\eta_{1} \\
\eta_{2}
\end{array}\right)=\left(\begin{array}{c}
0 \\
0.244 \eta_{2}
\end{array}\right)+\left(\begin{array}{c}
-0.270 \xi_{1}+1.975 \xi_{2}-0.365 \xi_{3} \\
-0.156 \xi_{4}
\end{array}\right)+\left(\begin{array}{l}
\zeta_{1} \\
\zeta_{2}
\end{array}\right) \\
& \left(\begin{array}{l}
\eta_{1} \\
\eta_{2}
\end{array}\right)=\left(\begin{array}{c}
-0.270 \xi_{1}+1.975 \xi_{2}-0.365 \xi_{3}+\zeta_{1} \\
0.2442 \eta_{2}-0.241 \xi_{4}+\zeta_{2}
\end{array}\right)
\end{aligned}
$$

Equation 31 is the matrix representation of the model relating latent variables for female's respondents in the study. Where $\eta_{1}$ and $\eta_{2}$ are the latent endogenous variables, $\xi_{1}, \xi_{2}$, $\xi_{3}$ and $\xi_{4}$ are latent exogenous variables.

$\zeta_{1}$ and $\zeta_{2}$ are the structural errors in dependent latent variables.

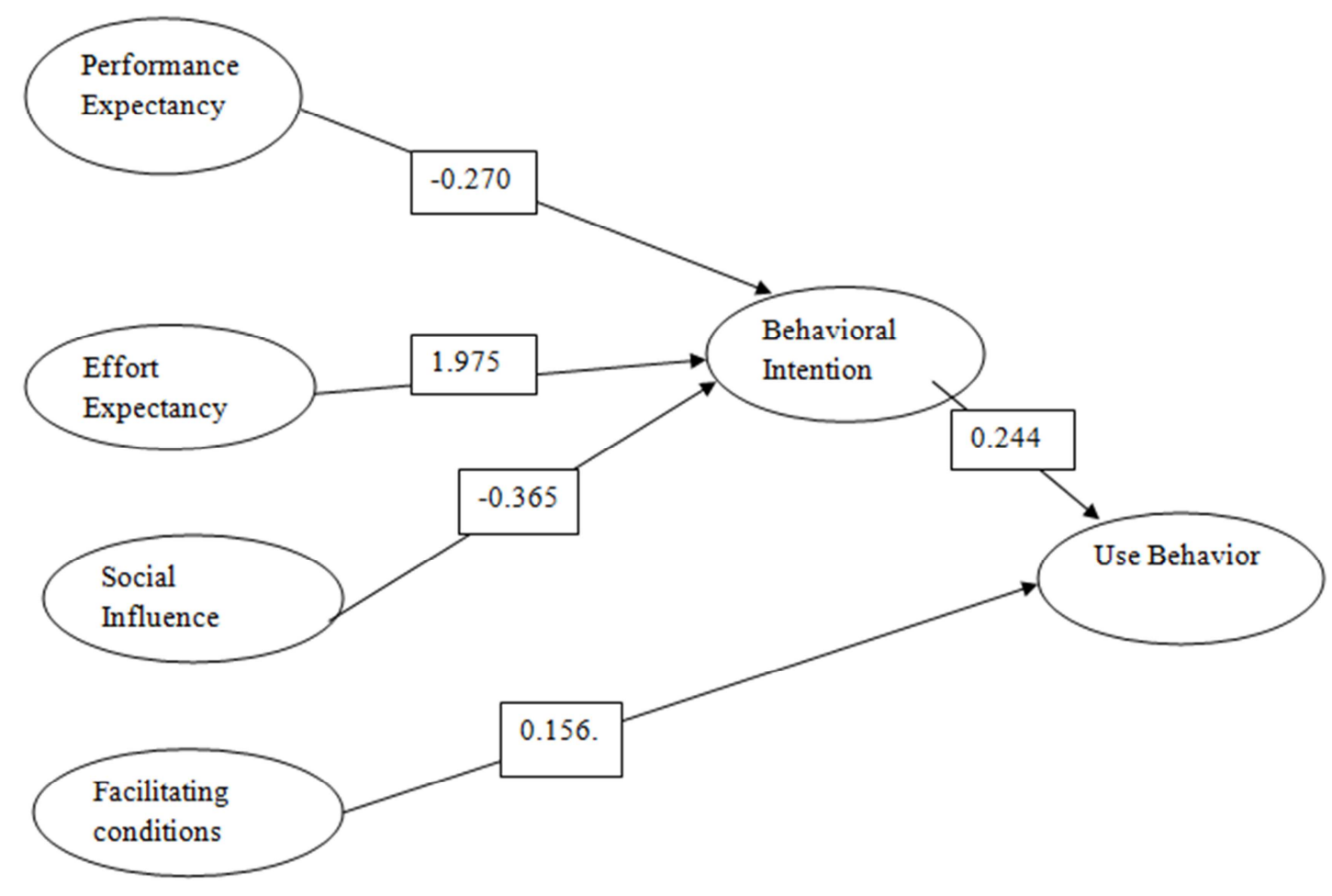

Figure 5. Diagram for female moderation.

Figure 5 is a pictorial representation of the structural equation model indicating the paths connecting the exogenous variables (Performance Expectancy, Effort Expectancy, Social Influence and Facilitating Conditions), and the endogenous variables (Behavioral Intention and Use Behavior) for female moderation.

\section{Summary and Conclusion}

This chapter presents summary of key findings and conclusion drawn from the study. The summary and conclusion are based on each specific objective.

The research findings indicated that in the overall structural equation model; the independent variables Performance Expectancy, Effort Expectancy and Social
Influence had significant influence on Behavioral Intention towards the use of a given Mobile Money

Transfer service. From the research findings Facilitating Conditions had no significant influence in adoption and use of a given Mobile Money Transfer System. However, Facilitating Conditions was found to be a significant factor in predicting adoption and use of Mobile Money Transfer for males and females where gender is a moderating factor.

Performance Expectancy was found to be a significant determinant of Behavioral Intention, this means that mobile phone users with high Performance Expectancy are more likely to adopt a given Mobile Money Transfer services. Therefore the mobile money service providers should ensure the Mobile Money Transfer improves the user's job performance and also increases user's productivity. 
Effort Expectancy was found to influence Behavioral Intention, meaning that the mobile money service providers should ensure that the service is easy to use and clear and understandable to users. The mobile money services providers should ensure that is easy for MMT's users to be skillful at using their Mobile Money Transfer service. Also the mobile money services providers should ensure that integration of their MMT's with banks is good.

Social Influence was found to influence Behavioral Intention to use a given Mobile Money Transfer service. This implies that the mobile phone users are influenced by people who are important to them. Also many mobile phone users tend to use a given Mobile Money Transfer service since many people have supported its use.

Since the independent variable namely, Performance Expectancy, Effort Expectancy and Social Influence had significant influence on Behavioral Intention towards the use of a given Mobile Money Transfer service. This means that the MMT's users would continue to use a given Mobile Money Transfer service they have chosen.

Facilitating Conditions was found to be a significant factor in predicting adoption and use of Mobile Money Transfer for males and females where gender is a moderating factor. This means that the Mobile Network Operators should provide necessary facilitating conditions to use their system such as agents.

Also from the findings the money transfer services should be more appropriate compared to others in terms of cost and security of money stored or sent through their networks.

The Mobile Network Operators should ensure that the users have the necessary knowledge to use the services that is the users are conversant with the cost of transactions. The study findings also indicated that the Mobile Network

Operators should ensure that there is a specific person (or group of people) that are available to provide assistance to mobile phone users when there are difficulties while using MMT's, that is the customer services providers should be available and efficient.

The findings indicated that Gender moderates adoption and usage of mobile money transfer services. Effort Expectancy, Social Influence and Facilitating Conditions were found to be significant determinants of Behavioral Intention and Use Behavior for male respondents. Female respondents are less influenced by Performance Expectancy, Effort Expectancy and Social Influence in adoption and usage of a given mobile money transfer service but they are influenced by Facilitating Conditions and Behavioral Intention when gender is used as a moderating factor.

\section{References}

[1] Awwad, Mohammad Suleiman (2009), 'Application of structural equation modeling to investigate factors affecting the intention to adopt internet banking in jordan', Jordan Journal of Business Administration Vol 5(2).

[2] Baker, S.R. (2007), 'Testing a conceptual model of oral health: a structural equation modeling approach', International and American Associations for Dental Research Vol 86(8), 708712 .

[3] Barrett, P (2007), 'Structural equation modeling: Adjudging model fit', Personality and Individual Differences 42 (5), 815-24.

[4] Bollen, K. A (1989), 'Structural equations with latent variables'.

[5] Bryne, B. M (2013), Structural Equation Modeling With Amos: Basic Concepts, Applications, and Programming, Second Edition., Routledge Press.

[6] Byrne, B (1998), Structural equation modelling with LISREL, PRECIS, and SIMPLIS., Hillsdale, NJ: Lawrence Erlbaum.

[7] Chin, W. W. and P. A. Todd (1995), On the Use, Usefulness, and Ease of Use of Structural Equation Modeling in MIS Research: A Note of Caution,"MIS Quarterly.

[8] Diamantopoulos, A. and J. A Siguaw (2000), Introducing LISREL, London: Sage Publications.

[9] Gefen, D., W. Straub and M. Boudreau (2000), 'Structural equation modeling techniques and regression: Guidelines for research practice', Communications of AIS Volume 4, Article 7 2.

[10] Hooper, D., J. Coughlan and R Mullen, M. (2008), 'Structural equation modeling: Guidelines for determining model fit.', The Electronic Journal of Business Research Methods Volume 6(Issue 1), pp. $53-60$.

[11] Hu, L.T. and P.M Bentler (1999), 'Cutoff criteria for fit indexes in covariance structure analysis: Conventional criteria versus new alternatives', Structural Equation Modeling.

[12] Joreskog, K. G. and D Sorbom (1993), 'Lisrel 8: Structural equation modeling with the simplis command language', Chicago: Scientific Software International.

[13] Kabbucho, Kamau, Cerstin Sander and Peter Mukwana (2003), ""passing the buck- money transfer systems: The practice and potential for products in Kenya"', MicroSave Africa Report.

[14] Kaplan, D. (2000), Structural Equation Modeling; Foundations and Extensions., Sage, Newbury Park, CA.

[15] Mason, M. and O. Lineth (2007), 'Poverty reduction through enhanced rural access to financial services in Kenya. Institute for policy analysis and research (ipar)', Southern and Eastern Africa Policy Research Network (SEAPREN) Working Paper No. 6 .

[16] Maurer, B., J. Kendall and C. Veniard (2011), 'An emerging platform: From money transfer system to mobile money ecosystem', Innovations: Technology, Governance, Globalization 6(4), 49-64.

[17] Mbiti, Isaac and David N. Weil (2011), 'Mobile banking: The impact of M-pesa in Kenya', NBER WORKING PAPER SERIES.

[18] Rosseel, Yves (2012), 'lavaan: An r package for structural equation modeling.' Journal of Statistical Software 48(2), 1-36.

[19] Schumaker, R. E. and R. G. Lomax (2004), 'A Beginners Guide to Structural Equation Modeling', Routledge. 
[20] Tobbin, P. E (2010), Modeling adoption of mobile money transfer: A consumer behavior analysis, in 'Paper presented at The 2nd International Conference on Mobile Communication Technology for Development, Kampala, Uganda. General'.

[21] Tobbin, Peter (2011), 'Adoption of mobile money transfer technology: Structural equation modeling approach', European Journal of Business and Management 3(7).

[22] Ullman, J. B. (2006), 'Structural equation modeling: Reviewing the basics and moving forwad.' Journal of Personality Assessment 85(1).
[23] Ullman, J.B (1996), 'Structural equation modeling (in: Using multivariate statistics, third edition, b.g. tabachnick and l.s. fidell, eds.)', HarperCollins College Publishers. New York, NY. pp. 709-819.

[24] Venkatesh, V., M. G. Morris, G. B. Davis and F. D Davis (2003), 'User acceptance of Information technology: Toward a unified view.', MIS Quarterly 27(3), 425-478.

[25] Yamane, Taro (1967), Statistics: An Introductory Analysis, 2nd Ed., New York: Harper and Row. 